\title{
Analysis of gene expression in different stages of MeIQx-induced rat hepatocarcinogenesis
}

\author{
JIN SEOK KANG ${ }^{1}$, HIDEKI WANIBUCHI ${ }^{1}$, TAKASHI MURAI ${ }^{1}$, \\ KEIICHIROU MORIMURA ${ }^{1}$, ANNA KINOSHITA ${ }^{1}$ and SHOJI FUKUSHIMA ${ }^{1,2}$ \\ ${ }^{1}$ Department of Pathology, Osaka City University Medical School, 1-4-3 Asahi-machi, Abeno-ku, \\ Osaka 545-8585; ${ }^{2}$ Japan Bioassay Research Center, 2445 Hirasawa Hadano, Kanagawa 257-0015, Japan
}

Received October 16, 2006; Accepted December 1, 2006

\begin{abstract}
To clarify hepatocarcinogenesis by the heterocyclic amine, 2-amino-3,8-dimethylimidazo[4,5-f]quinoxaline (MeIQx), we investigated the global expression of genes in rat liver. Rats were continuously fed MeIQx $100 \mathrm{ppm}$ in their diet, and were sacrificed at weeks 4 and 16 for early time points, and week 104 for tumor sampling. Global expression analysis using oligonucleotide microarrays (Affimetrix Gene Chip, Rat Genome 2302.0 Array) was carried out to detect altered genes in MeIQx-treated liver at 4 and 16 weeks $(n=5$, each), MeIQx-induced hepatocellular adenomas (HCA; $n=3$ ), and hepatocellular carcinomas (HCC; $n=3)$, compared with age-matched normal livers $(n=5)$. To investigate functional networks and gene ontology, two clusters were analyzed by Ingenuity Pathway Analysis. Clustering analysis of global genes demonstrated gene profiles of HCA and HCC to greatly differ from those of age-matched normal liver. However, after treatment with MeIQx for 4 or 16 weeks, no major differences were apparent. Ingenuity Pathway Analysis suggested pathways related to the cell cycle and glutathione metabolism may be involved in MeIQx-induced hepatocarcinogenesis. Real-time PCR analysis confirmed elevation of cyclin B1, cell division cycle 2, glutathione peroxidase 2 and glutathione $S$-transferase A2 in tumors, but not in early stage livers. In conclusion, molecular signatures of MeIQx-induced tumors clearly vary from that of age-matched normal liver, but no such shift is evident at early stages of hepatocarcinogenesis.
\end{abstract}

\section{Introduction}

Dietary and environmental carcinogens have an inevitable impact on our everyday lives, and may be closely related with

Correspondence to: Dr Shoji Fukushima, Japan Bioassay Research Center, 2445 Hirasawa Hadano, Kanagawa 257-0015, Japan

E-mail: s-fukushima@jisha.or.jp

Abbreviations: MeIQx, 2-amino-3,8-dimethylimidazo[4,5$f$ lquinoxaline); HCA, hepatocellular adenoma; HCC, hepatocellular carcinoma

Key words: MeIQx, microarray, rat, liver, HCA, HCC occurrence of cancer $(1,2)$. There are many genotoxic agents occurring naturally in our environment, including several heterocyclic amines such as 2-amino-3,8-dimethylimidazo[4,5f]quinoxaline (MeIQx), 2-amino-3,4-dimethylimidazo[4,5$f$ ]quinoline (MeIQ), 2-amino-3-methylimidazo[4,5-f]quinoline (IQ), and 2-amino-1-methyl-6-phenylimidazo[4,5-b]pyridine (PhIP), which induce mutations and tumors $(3,4)$.

MeIQx is generated when beef, chicken and mutton are cooked, and it is believed that its genotoxicity results from metabolism of the parent compound to electrophilic intermediates causing DNA-adducts $(5,6)$. It exerts carcinogenicity in both mice and rats (7-9). However, the carcinogenic mechanism of MeIQx is not fully understood.

The recent development of large-scale gene expression profiling by microarrays now allows for the concurrent analysis of many genes in a short time, with advantages for understanding multiple steps in carcinogenesis, and in screening to identify carcinogens $(10,11)$. However, most of the previous microarray studies mainly focused on tumor profiles compared to counterpart normal tissues $(12,13)$, and there is only limited information on the sequential changes in expression during multistep carcinogenesis. Therefore, it is important to understand carcinogenesis and compare the gene profiles between early stages and tumors.

To gain a better understanding of molecular mechanisms of MeIQx-induced rat liver carcinogenesis, we performed oligonucleotide microarrays using livers of rats treated with MeIQx or normal diet, and compared global gene alterations at weeks 4 and 16 and in hepatocellular adenomas (HCAs) and hepatocellular carcinomas (HCCs) at 104 weeks with those of normal age-matched livers.

\section{Materials and methods}

Animals and treatment. Male F344 rats were obtained from Charles River Japan, Inc. (Atsugi, Japan), and housed in a room maintained on a 12-h light/dark cycle, at constant temperature and humidity. They were allowed free access to pellet chow (MF-1, Oriental Yeast Co., Tokyo, Japan) during the experiment. All procedures were approved by the Institutional Animal Care and Use Committee of Osaka City University Medical School.

Animals were fed with or without MeIQx 100 ppm (Oriental MF, Oriental Yeast Co. Tokyo), and were sacrificed 
a

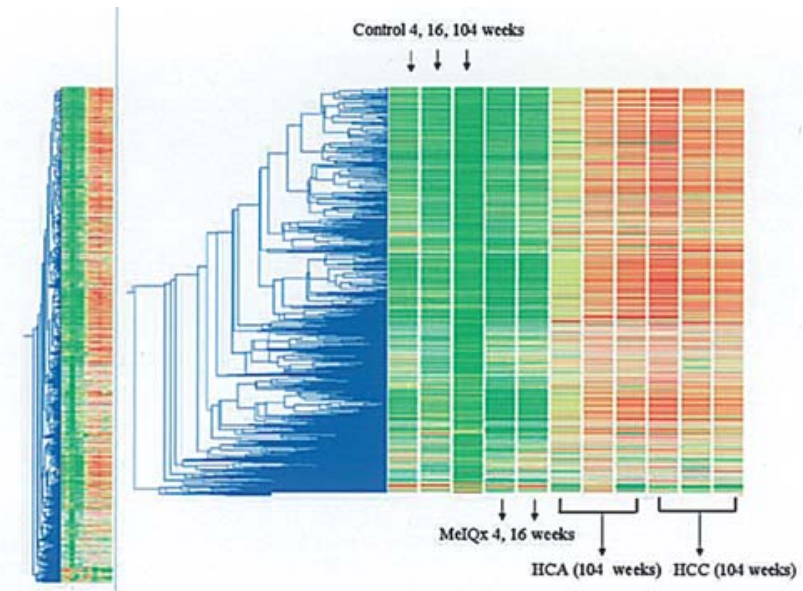

b



Figure 1. Gene expression in livers from F344 rats treated with MeIQx $100 \mathrm{ppm}$ for 4, 16 and 104 weeks. Four categories of MeIQx (4 and 16 weeks), and HCA and HCC (104 weeks, respectively) were classified, and analyzed, showing close correlation between 4 and 16 weeks, and between HCAs and HCCs. Gene profile patterns of samples (a) and clustering analysis of genes induced by MeIQx (b). HCA, hepatocellular adenoma; HCC, hepatocellular carcinoma.

at weeks 4 and 16 for early time points, and week 104 for a tumor occurring point. At necropsy, basal diet-treated normal liver and MeIQx-treated liver for 4 and 16 weeks $(n=5$, respectively) were fixed in $10 \%$ phosphate-buffered formalin, and routinely processed for embedding in paraffin, and staining of $4-\mu \mathrm{m}$ sections with hematoxylin and eosin for histopathological examination. At 104 weeks, age-matched normal liver $(n=5)$, MeIQx-induced HCAs $(n=3)$, and HCCs $(n=3)$ were taken for histopathological examination. Liver and liver nodules from all of the animals treated with or without MeIQx for 4, 16 or 104 weeks were also snap-frozen in liquid nitrogen for RNA extraction and subsequent analysis.

RNA isolation, cRNA prepration and microarray hybridization. Approximately $100 \mathrm{mg}$ of frozen tissue was homogenized and total RNA was isolated using Isogen (Nippon Gene Co. Ltd, Tokyo, Japan), isopropanol precipitated, dissolved in DEPCtreated distilled water and stored at $-80^{\circ} \mathrm{C}$ until use. RNA concentrations were determined with a spectrophotometer (Ultraspec 3000, UV/Visible Spectrophotometer; Pharmacia
Biotech, Tokyo, Japan). The quality of the isolated RNA was assessed by measuring the absorbance at $260 \mathrm{~nm}$, analyzing the A260/A280 ratio (1.7-2.0), and evaluating the integrity of $28 \mathrm{~S}$ and 18S RNA bands on $1 \%$ agarose gels.

Isolated RNAs from age-matched normal liver and MeIQxtreated liver after 4 or 16 weeks were each pooled to give single samples. Isolated RNAs from MeIQx-induced HCAs and HCCs were separately processed.

A $12 \mu \mathrm{g}$ aliquot of total RNA was processed for poly-A RNA enrichment and generation of cDNA probes using an Affymetrix cDNA synthesis kit (Affymetrix) according to the manufacturer's protocol. Biotin-labeled antisense cRNA was synthesized by the in vitro transcription reaction (IVT) using an RNA transcript labeling kit (Affymetrix), purified, fragmented, and hybridized to an oligonucleotide microarray (Affimetrix Gene Chip, Rat Genome 230 2.0 Array) according to the manufacturer's instructions (Affymetrix).

The arrays were washed and stained with R-phycoerythrin conjugated streptavidin (Molecular Probes, OR, USA) and then scanned with an Affymetrix GeneChip Scanner 3000. Raw intensity values were normalized to positive control genes and each gene was normalized to the age-matched control using GeneSpring software version 7.2 (Silicon Genetics, Redwood City, CA, USA). The log ratio of the hybridization intensity of samples was used to represent the relative gene expression level. Comparisons of gene expression across the groups were performed using Venn diagrams and clustering was performed with the Condition Tree algorithm.

Ingenuity pathway analysis. To investigate functional network and gene ontology, two clusters showing upregulation in a time-dependent manner were selected and analyzed using Ingenuity pathway analysis (IPA). Gene accession numbers were imported into IPA software version 2.0 (Ingenuity Systems, Mountain View, CA, USA). The genes were categorized based on location, cellular components, and reported or suggested biochemical, biologic, and molecular functions using the software. The identified genes were also mapped to genetic networks available in the Ingenuity database and then ranked by score.

Real-time reverse transcription polymerase chain reaction (RT-PCR) analysis. For cDNA synthesis, $3 \mu \mathrm{g}$ of total RNA was heated to $70^{\circ} \mathrm{C}$ for $10 \mathrm{~min}$ and then placed immediately on ice for $10 \mathrm{~min}$. To each sample, $4 \mu 1$ of $5 \mathrm{X}$ first strand buffer, $2 \mu 1$ of $0.1 \mathrm{M}$ DTT, $4 \mu 1$ of $2 \mathrm{mM}$ dNTP mix, $1 \mu 1$ of oligo(dT) primer, and $1 \mu 1$ of Superscript II reverse transcriptase (Invitrogen, CA) were added. Reverse transcription was then performed at $42^{\circ} \mathrm{C}$ for $50 \mathrm{~min}$, followed by heating to $70^{\circ} \mathrm{C}$ for $15 \mathrm{~min}$, and cDNA samples were stored at $-20^{\circ} \mathrm{C}$ until assayed. cDNAs were amplified using specific oligonucleotide primers for rat cyclin B1, cell division cycle 2, glutathione peroxidase 2 and glutathione $S$-transferase A2 using TaqMan ${ }^{\circledR}$ gene expression assays according to the manufacturer's instructions (Applied Biosystems, CA, USA). The PCR program cycles were set as follows: initial denaturing at $95^{\circ} \mathrm{C}$ for $20 \mathrm{sec}$, followed by 40 cycles at $95^{\circ} \mathrm{C}$ for $3 \mathrm{sec}$, and $60^{\circ} \mathrm{C}$ for $30 \mathrm{sec}$.

GAPDH mRNA was employed as an internal standard, and cyclin B1, cell division cycle 2 , glutathione peroxidase 2 

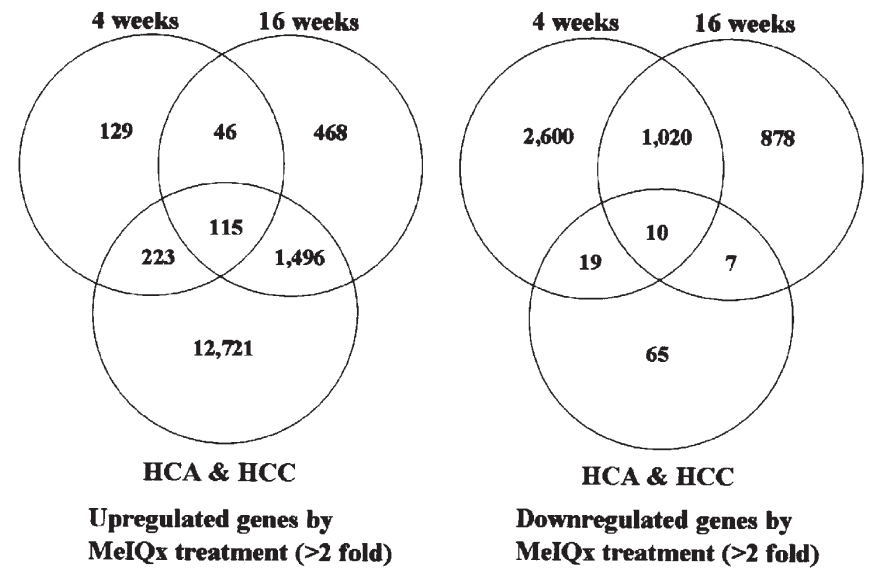

Figure 2. Gene alteration by MeIQx treatment. Venn diagram of changes of gene expression in rat liver treated with $100 \mathrm{ppm}$ MeIQx. Circles represent MeIQx treatment for 4 or 16 weeks or MeIQx-induced HCAs and HCCs with genes identified by microarray analysis as upregulated or downregulated at least 2-fold compared with age-matched normal livers. HCA, hepatocellular adenoma; HCC, hepatocellular carcinoma

and glutathione $S$-transferase A2 mRNA expression were determined by real-time quantitative PCR and normalized against GAPDH mRNA levels. All PCR products were amplified in a linear cycle. Data were the mean \pm SD from all individual samples per group and three independent experiments.

Statistical analysis. Statistical analyses were performed with the Tukey-Kramer method using the JMP program (SAS Institute, Cary, NC). For all comparisons, probability values less than 5\% $(p<0.05)$ were considered to be statistically significant.

\section{Results}

Microarray. Gene profiles for livers from controls at weeks 4, 16 and 104 and after MeIQx treatment at weeks 4 and $16(n=1$ as pooling, respectively), as well as for MeIQx-induced HCAs and HCCs at weeks 104 ( $n=3$, respectively) are presented in Fig. 1. Gene profiles for the HCAs and HCCs greatly differed from those of age-matched normal liver, but this was not the case after MeIQx treatment for 4 or 16 weeks (Fig. 1A). Clustering analysis of global gene profiles for HCAs and HCCs demonstrated a close relationship (Fig. 1B).

Changes of gene expression in rat liver treated with 100 ppm MeIQx are presented in Fig. 2. Genes upregulated more than two-fold compared with age-matched controls numbered 513, 2125 and 14555 and downregulated genes numbered 3649,1915 and 101 at 4 weeks, 16 weeks in HCAs and HCCs, respectively.

Table I. Genes associated with cell cycle: G2/M DNA damage checkpoint regulation from cluster 1.

\begin{tabular}{|c|c|c|c|c|c|c|c|}
\hline \multirow[b]{2}{*}{ Gene name } & \multirow[b]{2}{*}{ Description } & \multicolumn{4}{|c|}{ Expression value (log ratio) } & \multirow[b]{2}{*}{ Family } & \multirow[b]{2}{*}{ Location } \\
\hline & & 4 weeks & 16 weeks & $\mathrm{HCA}$ & $\overline{\mathrm{HCC}}$ & & \\
\hline CCNB1 & Cyclin Bl & -0.284 & -0.168 & 2.311 & 3.309 & Kinase & Nucleus \\
\hline $\mathrm{CCNB} 2$ & Cyclin B2 & -0.607 & -0.245 & 2.495 & 3.264 & & Nucleus \\
\hline $\mathrm{CDC} 2$ & $\begin{array}{l}\text { Cell division cycle } 2, \\
\text { G1 to } \mathrm{S} \text { and } \mathrm{G} 2 \text { to } \mathrm{M}\end{array}$ & -0.501 & -0.388 & 2.856 & 3.611 & Kinase & Nucleus \\
\hline BRCA1 & Breast cancer 1 & -0.377 & 0.065 & 1.683 & 2.325 & $\begin{array}{l}\text { Transcription } \\
\text { regulator }\end{array}$ & Nucleus \\
\hline BTRC & $\begin{array}{l}\text { ß-transducin repeat } \\
\text { containing }\end{array}$ & -0.362 & -0.297 & 1.673 & 1.813 & Enzyme & Cytoplasm \\
\hline PLK1 & Polo-like kinase 1 & -0.217 & 0.197 & 3.521 & 4.105 & Kinase & Nucleus \\
\hline TOP2A & $\begin{array}{c}\text { Topoisomerase } \\
\text { (DNA) II } \alpha 170 \mathrm{kDa}\end{array}$ & 0.115 & -0.056 & 2.315 & 3.002 & Enzyme & Nucleus \\
\hline WEE1 & $\begin{array}{l}\text { WEE1 homolog } \\
\text { tyrosine 3- }\end{array}$ & -1.522 & 0.252 & 2.177 & 2.893 & Kinase & Nucleus \\
\hline YWHAB & $\begin{array}{l}\text { Monooxygenase/ } \\
\text { tryptophan 5- } \\
\text { monooxygenase } \\
\text { activation protein, } \\
\text { ß polypeptide }\end{array}$ & 0.395 & -0.155 & 1.64 & 1.959 & & \\
\hline
\end{tabular}


Table II. Genes associated with glutathione metabolism from clusters 1 and 2.

\begin{tabular}{|c|c|c|c|c|c|c|c|}
\hline \multirow[b]{2}{*}{ Gene name } & \multirow[b]{2}{*}{ Description } & \multicolumn{4}{|c|}{ Expression value (log ratio) } & \multirow[b]{2}{*}{ Family } & \multirow[b]{2}{*}{ Location } \\
\hline & & 4 weeks & 16 weeks & $\mathrm{HCA}$ & $\mathrm{HCC}$ & & \\
\hline GPX2 & Glutathione peroxidase 2 & 0.176 & 0.283 & 3.891 & 4.365 & Enzyme & Cytoplasm \\
\hline GPX3 & Glutathione peroxidase 3 & -0.189 & 0.214 & 2.445 & 2.109 & Enzyme & $\begin{array}{c}\text { Extracellular } \\
\text { space }\end{array}$ \\
\hline GSTA2 & Glutathione $S$-transferase A2 & 0.482 & 1.634 & 2.057 & 3.208 & Enzyme & Cytoplasm \\
\hline GSTM1 & Glutathione $S$-transferase M1 & -0.694 & 0.231 & 2.129 & 2.838 & Enzyme & Cytoplasm \\
\hline GSTM2 & Glutathione $S$-transferase M2 & 0.019 & 1.109 & 1.049 & 1.735 & Enzyme & Cytoplasm \\
\hline GSTM4 & Glutathione $S$-transferase M4 & -0.549 & -0.01 & 1.237 & 2.715 & Enzyme & Cytoplasm \\
\hline GSTP1 & Glutathione $S$-transferase $\pi$ & -0.097 & -0.365 & 3.278 & 3.548 & Enzyme & Cytoplasm \\
\hline G6PD & $\begin{array}{c}\text { Glucose-6-phosphate } \\
\text { dehydrogenase }\end{array}$ & -6.05 & 0.453 & 2.897 & 2.481 & Enzyme & Cytoplasm \\
\hline GCLM & $\begin{array}{c}\text { Glutamate-cysteine ligase } \\
\text { modifier subunit }\end{array}$ & -0.311 & -0.293 & 2.267 & 2.807 & Enzyme & Cytoplasm \\
\hline
\end{tabular}

HCA, hepatocellular adenoma; HCC, hepatocellular carcinoma.



Figure 3. Analysis of clusters by Ingenuity pathway systems. A1, MeIQx treatment for 4 weeks; A2, MeIQx treatment for 16 weeks; A3, hepatocellular adenomas (HCAs); A4, hepatocellular carcinoma (HCCs). The red horizontal lines denote the cutoff point for significance.

There were a small number of commonly upregulated and downregulated genes (115 and 10, respectively), which were mostly found to be EST (data not shown).

Ingenuity pathway analysis for clusters 1 and 2 suggested pathway involved in the cell cycle and glutathione metabolism to be targeted by MeIQx-induced hepatocarcinogenesis (Tables I and II, Fig. 3).
Real-time RT-PCR analysis. Real-time RT-PCR analysis was utilized for validation and confirmed alterations in cyclin B1, cell division cycle 2, glutathione peroxidase 2 and glutathione $S$-transferase A2 in the liver.

There was a significant increase in expression of these four genes in tumors (HCA and/or HCC) compared to agematched controls $(\mathrm{p}<0.05$ or $\mathrm{p}<0.01)$. There were also 



Figure 4. Real-time RT-PCR analysis of cyclin B1, cell division cycle 2, glutathione peroxidase 2 and glutathione $S$-transferase A2 in the liver. The mRNAs were quantified and normalized against GAPDH mRNA expression as described in the Materials and methods. Note the significant increase in these four genes' expression in tumors (HCA and/or HCC) compared to age-matched controls $(\mathrm{p}<0.05$ or $\mathrm{p}<0.01$ ). There were also differences of cyclin B1 at 4 weeks and glutathione $S$-transferase A2 at 16 weeks of treatment of MeIQx compared with age-matched control $(\mathrm{p}<0.05)$. Data are the mean \pm SD from all individual samples per group and three independent runs; significantly different from respective control group ( $\mathrm{p}<0.05,{ }^{* *} \mathrm{p}<0.01$, respectively). HCA, hepatocellular adenoma; HCC, hepatocellular carcinoma.

differences in cyclin B1 at 4 weeks and glutathione $S$ transferase A2 at 16 weeks with MeIQx treatment compared with age-matched controls ( $\mathrm{p}<0.05)$ (Fig. 4).

\section{Discussion}

In this study, analysis of gene expression in MeIQx-induced rat hepatocarcinogenesis showed the molecular signatures of MeIQx-induced tumors to clearly differ from those of agematched normal liver, but without any consistent shift evident at early stages of hepatocarcinogenesis.

It is reasonable that the differences in gene expression profiles between the liver treated with MeIQx for 4 or 16 weeks and age-matched normal liver should be less pronounced than with tumors. Even though there were many altered genes in HCAs and HCCs, we could not find any meaningful examples which were altered in common from early stages onwards. However, early focal lesions only constitute a very small proportion of the tissue and surrounding parenchyma would be expected to determine the profile. To overcome this, microdissection analysis can be applied, as shown in a study of esophageal carcinogenesis (14). A recent report suggested specific differences in gene expression profile between GST-P positive rat liver foci and surrounding tissue (15), but existence of tumor markers in non-GST-P lesions
(16) may also indicate the possibility of losing important carcinogenesis-related genes when researchers focus on restricted altered areas.

In the present study, we obtained evidence that pathways of cell cycle and glutathione metabolism are involved in MeIQx-induced liver carcinogenesis by Ingenuity pathway analysis for clusters 1 and 2. It thus seems that gene selection by the pathway analysis approach may allow a better understanding of the mechanisms of rat liver chemical carcinogenesis, as recently reported $(17,18)$. It is commonly believed that increased cell turnover results in the selection of monoclonal hepatocyte populations that subsequently undergo genomic alterations leading to the development of HCAs and HCCs, which usually show deregulation of cell cycling $(19,20)$. In general, glutathione metabolism is related to detoxification of xenobiotics and maintenance of the redox state. However, elevated levels of glutathione have been found in tumor cells $(21,22)$. In experimental models, expression of glutathione $S$-transferases is upregulated in foci and nodules, although some carcinomas showed downregulation at end stages (23).

Our previous study showed that oral administration of MeIQx $100 \mathrm{ppm}$ induced preneoplastic lesions at early time points $(24,25)$, and tumors in the long term in livers of rats (8). Two-week treatments with MeIQx induced the 
upregulation of cytochrome P450 (CYP) 1A2 and 2C11 (26), but this was not apparent at the 4 and 16-week stages.

There has been a trend recently in focusing on toxicogenomic profiles after short-term treatment of some chemicals in vivo (27-29). However, our data suggest there may be limited alterations of genes at early time points and the profiles from early lesions may be different from those of tumors. Therefore, it is very important to set a relevant exposure time for carcinogens, with an awareness of relations between short-term and long-term profiles. Further studies are thus warranted to analyze detailed alterations from early to late stages of heterocyclic amine-induced carcinogenesis, so that any chemopreventive strategy can be based on a firm foundation.

\section{Acknowledgements}

We would like to thank Ms. Kaori Touma, Masayo Imanaka, and Rie Onodera for their technical assistance, and Ms. Mari Dokoh, Yuko Onishi, and Yoko Shimada for their help during preparation of this manuscript. This research was supported by Grants-in-Aid for Cancer Research from the Ministry of Health, Labour and Welfare of Japan.

\section{References}

1. Sugimura T: Studies on environmental chemical carcinogenesis in Japan. Science 233: 312-318, 1986.

2. Sugimura T, Wakabayashi K, Nakagama $\mathrm{H}$ and Nagao M: Heterocyclic amines: mutagens/carcinogens produced during cooking of meat and fish. Cancer Sci 95: 290-299, 2004.

3. Nagao M, Ushijima T, Toyota M, Inoue R and Sugimura T: Genetic changes induced by heterocyclic amines. Mutat Res 376: 161-167, 1997.

4. Nagao M: A new approach to risk estimation of food-borne carcinogen--heterocyclic amines--based on molecular information. Mutat Res 431: 3-12, 1999.

5. Rich KJ, Murray BP, Lewis I, Rendell NB, Davies DS, Gooderham NJ and Boobis AR: $N$-hydroxy-MeIQx is the major microsomal oxidation product of the dietary carcinogen MeIQx with human liver. Carcinogenesis 13: 2221-2226, 1992.

6. Turesky RJ, Lang NP, Butler MA, Teitel CH and Kadlubar FF: Metabolic activation of carcinogenic heterocyclic aromatic amines by human liver and colon. Carcinogenesis 12: 1839-1845, 1991.

7. Kato T, Ohgaki H, Hasegawa H, Sato S, Takayama $\mathrm{S}$ and Sugimura T: Carcinogenicity in rats of a mutagenic compound, 2-amino-3,8-dimethylimidazo[4,5-f]quinoxaline. Carcinogenesis 9: 71-73, 1988 .

8. Kushida H, Wakabayashi K, Sato H, Katami M, Kurosaka R and Nagao M: Dose-response study of MeIQx carcinogenicity in F344 male rats. Cancer Lett 83: 31-35, 1994.

9. Ohgaki H, Hasegawa H, Suenaga M, Sato S, Takayama S and Sugimura T: Carcinogenicity in mice of a mutagenic compound, 2-amino-3,8-dimethylimidazo[4,5-f]quinoxaline (MeIQx) from cooked foods. Carcinogenesis 8: 665-668, 1987.

10. Butte A: The use and analysis of microarray data. Nat Rev Drug Discov 1: 951-960, 2002.

11. Clarke PA, te Poele R and Workman P: Gene expression microarray technologies in the development of new therapeutic agents. Eur J Cancer 40: 2560-2591, 2004.

12. Delpuech O, Trabut JB, Carnot F, Feuillard J, Brechot C and Kremsdorf D: Identification, using cDNA macroarray analysis, of distinct gene expression profiles associated with pathological and virological features of hepatocellular carcinoma. Oncogene 21: 2926-2937, 2002.
13. Chuma M, Sakamoto M, Yamazaki K, Ohta T, Ohki M, Asaka M and Hirohashi S: Expression profiling in multistage hepatocarcinogenesis: identification of HSP70 as a molecular marker of early hepatocellular carcinoma. Hepatology 37: 198-207, 2003.

14. Nishida $\mathrm{K}$, Mine S, Utsunomiya $\mathrm{T}$, Inoue $\mathrm{H}$, Okamoto $\mathrm{M}$, Udagawa H, Hanai T and Mori M: Global analysis of altered gene expressions during the process of esophageal squamous cell carcinogenesis in the rat: a study combined with a laser microdissection and a cDNA microarray. Cancer Res 65: 401-409, 2005.

15. Suzuki S, Asamoto M, Tsujimura K and Shirai T: Specific differences in gene expression profile revealed by cDNA microarray analysis of glutathione S-transferase placental form (GST-P) immunohistochemically positive rat liver foci and surrounding tissue. Carcinogenesis 25: 439-443, 2004.

16. Sukata T, Uwagawa S, Ozaki K, Sumida K, Kikuchi K, Kushida M, Saito K, Morimura K, Oeda K, Okuno Y, Mikami N and Fukushima S: alpha(2)-Macroglobulin: a novel cytochemical marker characterizing preneoplastic and neoplastic rat liver lesions negative for hitherto established cytochemical markers. Am J Pathol 165: 1479-1488, 2004.

17. Kasamatsu A, Endo Y, Uzawa K, Nakashima D, Koike H, Hashitani S, Numata T, Urade M and Tanzawa H: Identification of candidate genes associated with salivary adenoid cystic carcinomas using combined comparative genomic hybridization and oligonucleotide microarray analyses. Int J Biochem Cell Biol 37: 1869-1880, 2005.

18. Cariello NF, Romach EH, Colton HM, Ni H, Yoon L, Falls JG, Casey W, Creech D, Anderson SP, Benavides GR, Hoivik DJ, Brown R and Miller RT: Gene expression profiling of the PPAR-alpha agonist ciprofibrate in the cynomolgus monkey liver. Toxicol Sci 88: 250-264, 2005.

19. Greenbaum LE: Cell cycle regulation and hepatocarcinogenesis. Cancer Biol Ther 3: 1200-1207, 2004.

20. Tannapfel A and Wittekind C: Genes involved in hepatocellular carcinoma: deregulation in cell cycling and apoptosis. Virchows Arch 440: 345-352, 2002

21. Balendiran GK, Dabur R and Fraser D: The role of glutathione in cancer. Cell Biochem Funct 22: 343-352, 2004.

22. Ketterer B: Protective role of glutathione and glutathione transferases in mutagenesis and carcinogenesis. Mutat Res 202: 343-361, 1988.

23. Stalker MJ, Kocal TE, Quinn BA, Gordon SG and Hayes MA: Reduced expression of glutathione S-transferase $\mathrm{Yb} 2$ during progression of chemically induced hepatocellular carcinomas in Fischer 344 rats. Hepatology 20: 149-158, 1994.

24. Fukushima S: Low-dose carcinogenicity of a heterocyclic amine, 2-amino-3,8-dimethylimidazo[4,5-f]quinoxaline: relevance to risk assessment. Cancer Lett 143: 157-159, 1999.

25. Fukushima S, Wanibuchi H, Morimura K, Wei M, Nakae D, Konishi Y, Tsuda H, Uehara N, Imaida K, Shirai T, Tatematsu M, Tsukamoto T, Hirose M, Furukawa F, Wakabayashi K and Totsuka Y: Lack of a dose-response relationship for carcinogenicity in the rat liver with low doses of 2-amino-3,8dimethylimidazo[4,5-f]quinoxaline or $N$-nitrosodiethylamine. Jpn J Cancer Res 93: 1076-1082, 2002.

26. Hokaiwado N, Asamoto M, Tsujimura K, Hirota T, Ichihara T, Satoh T and Shirai T: Rapid analysis of gene expression changes caused by liver carcinogens and chemopreventive agents using a newly developed three-dimensional microarray system. Cancer Sci 95: 123-130, 2004.

27. Ellinger-Ziegelbauer H, Stuart B, Wahle B, Bomann W and Ahr HJ: Characteristic expression profiles induced by genotoxic carcinogens in rat liver. Toxicol Sci 77: 19-34, 2004.

28. Bulera SJ, Eddy SM, Ferguson E, Jatkoe TA, Reindel JF, Bleavins MR and De La Iglesia FA: RNA expression in the early characterization of hepatotoxicants in Wistar rats by highdensity DNA microarrays. Hepatology 33: 1239-1258, 2001.

29. Michel C, Desdouets C, Sacre-Salem B, Gautier JC, Roberts R and Boitier E: Liver gene expression profiles of rats treated with clofibric acid: comparison of whole liver and laser capture microdissected liver. Am J Pathol 163: 2191-2199, 2003. 